\title{
The benefits of e-business adoption: an empirical study of Swedish SMEs
}

\author{
Hooshang M. Beheshti · Esmail Salehi-Sangari
}

Received: 15 September 2006/ Accepted: 15 November 2006/ Published online: 14 December 2006 (C) Springer-Verlag 2006

\begin{abstract}
The global nature of business today and the advances in information and communications technologies have compelled corporations to employ emerging technologies in order to remain competitive. In recent years electronic business has been adopted by many corporations to improve operational efficiency, profitability, and to strengthen their competitive position. This study examines the impact of web-based e-business on the small and medium-size enterprises (SMEs) in Sweden. The analyses of data collected for this study provide valuable information to the executives of manufacturing and service SMEs. The findings show that the SMEs in the sample have benefited from e-business implementation in both operational and performance areas of their organization.
\end{abstract}

Keywords E-business · E-strategy - Barriers to entry · Customer relations · Performance improvement

\section{Introduction}

The proliferation of the Internet has provided a unique opportunity for small and medium-size enterprises (SMEs) to conduct business electronically, to be more competitive, and to do business in a global environment. Implementing

\footnotetext{
H. M. Beheshti ( $\square)$

Department of Management, Radford University, Radford, VA 24142, USA

e-mail: hbehesht@radford.edu

E. Salehi-Sangari

Division of Industrial Marketing and e-Commerce, Lulea University of Technology,

Lulea, Sweden

e-mail: ess@ltu.se
} 
e-business and having an online presence can be beneficial for many companies with adequate preparation prior to implementation. The Internet usage in the European Union and Sweden grew by 147 and $68 \%$, respectively between 2000 and 2005. About half the populations in the European Union member states and $75 \%$ of the Swedes use the Internet (Internet Usage in Europe 2006).

Internet-based electronic business can be defined as a system that provides businesses with a platform to connect with customers, business partners, employees, and suppliers via the Internet, extranets, and intranets. The internal and external connectivity of electronic business enables companies to become more efficient by lowering costs, increasing productivity, and accomplishing business goals faster. In addition, responsiveness to customer needs, communications with businesses, and supplier relations and selection can be improved.

The benefits of joining the e-business arena outweigh the costs for most organizations (Barau et al. 2001; Lefebvre et al. 2005; Straub and Klein 2001). However, the review of the literature shows that SMEs are using the Internet in most part for electronic mail and advertising and are not taking full advantage of e-business technologies when compared to large organizations (Fillis et al. 2004; Peet et al. 2002; Quayle 2002; Grandon and Pearson 2004). Understanding how a company can benefit from e-business is the key to ebusiness implementation. Small and medium-size organizations must ensure that e-business will align with their organizational goals and in turn create positive outcomes for the organization. Having a well-developed strategy that includes flexibility and adaptability for launching, maintaining, and updating an e-business is crucial. E-business strategy can be defined as the development and the execution of a plan for a company to do business electronically. When developing an e-business strategy, companies must identify the areas of the business that will be affected by e-business implementation. The business owner/manager and key employees should participate in the development of a plan for e-business implementation and identify benefits derived and changes required by such a system. Managers should encourage customers and suppliers participation in this phase since the readiness of both for e-business are essential in the success of an e-business plan. The plan should include the type of information and communications technologies and security measures needed as well as provide methods for earning the trust of the customers, business partners, and suppliers. In addition, an entrance strategy must be developed. Entering into e-business at the wrong time can prove detrimental to an SME (Evans 1999; Wright 2000; Sanderson 2004; Cote et al. 2005).

Customers' expectations and needs change over time; therefore, a company must be ready to update its system in a timely fashion in order to meet the changing demand of the marketplace. Satisfying customer needs requires an effective marketing strategy that includes a customer relationship database which contains information about the customers' buying behavior and preferences. This database allows marketing efforts to be directed toward customer needs. An integrated program makes it possible for sales staff to view 
how current and prospective customers are reacting to new programs, what each customer is buying, and how they feel about pricing and customer service. The ability to better serve each customer leads to customer loyalty as well as improvement in the products and services offered by the firm.

The integration of e-business into business processes involves the incorporation of information and communication technologies into business activities so that business transactions can be performed online with data driven by corporate databases. For example, e-business integration with backoffice operations can improve inventory management, sales processing, order entry, and catalog development. In general, the development and implementation of marketing strategies for e-business necessitate substantial restructuring and rethinking of the existing processes. Managers must communicate the importance of e-business applications to their employees and provide training for them. Employees should understand what they are supposed to do and how they can make the venture successful for the company.

An e-business model is the electronic methods and structures used by a company to remain competitive and to generate revenue. There are several ebusiness models that can be used by an organization but the five common models include: business-to-business (B2B), business-to-consumer (B2C), portals, websites as goodwill or promotional vehicles, and mobile commerce. Companies should carefully analyze their business and evaluate the benefits and costs of each model to ensure that they utilize the best system for their business. The selection of a suitable model can lower intermediary costs, reduce purchasing costs, improve buyer and supplier relationships, and improve market share or development (Barau et al. 2001).

\section{E-business in manufacturing and service sectors}

The organizational structure of manufacturing and service organizations differ greatly in comparison and these sectors have different motives for implementing e-business. While a service organization is concerned with advertising their competence and abilities, a manufacturing organization is more concerned with getting their product out in the market for consumers. The service sector lacks the tangible products that a manufacturing firm possesses; therefore, they must create their name through exceptional customer service. Manufacturing companies need to research, develop, and promote a quality product that has premium after purchase warranties along with good customer service. Collaborative planning between the manufacturer and the supplier, distributor, and retailer is an essential part of the manufacturing strategy. For this reason, the use of collaborative tools in manufacturing organizations has increased with the introduction of the Internet and e-business applications. Implementing e-business can be expensive and if it fails, a company loses the time and money invested in the project and to an SME the failure could result in financial ruins. 
In general, e-business integration and applications for service organizations are less complex than manufacturing firms. Manufacturing firms have used various technologies such as material requirements planning (MRP), manufacturing resource planning (MRP II), flexible manufacturing systems (FMS), and computer integrated manufacturing (CIM) over the years in their operations and have more experience in new technology adoption and integration than service firms. However, manufacturing and service SMEs must exercise caution before deciding on e-business integration into their daily operations. The integration of e-business applications can be done in small steps to capitalize on the benefits of process improvement required by e-business implementation and to minimize the negative aspects of change and interruptions of daily business activities. Both sectors must realize that the success of an Internet-based e-business depends on a user-friendly website that is maintained and updated regularly.

\section{Research methodology and objectives}

The primary objective of this research is to examine the impact of the Internetbased e-business on the Swedish SMEs. The major research objectives are:

1. To decide the extent of electronic business integration and applications in Swedish SMEs.

2. To determine the length of implementation time and the degree of satisfaction with e-business.

3. To identify similarities and/or differences that exists between manufacturing and service SMEs with regard to the implementation and applications of electronic business.

4. To determine the common concerns of SMEs in the implementation and applications of electronic business.

5. To decide the benefits of electronic business implementation in SMEs.

In this study, we adopted the European Commission's definition of SME; that is, any firm that employs less than 250 employees. However, firms with employees of less than ten, very small, were excluded and considered not suitable for this research. Data was solicited from 500 randomly selected, Swedish companies having between 10 and 249 employees without regard to their location or industry for analysis. A four-page survey questionnaire with a cover letter explaining the objectives of the study, and a return envelope was mailed to these SMEs. The total number of usable responses after two mailings was $132(26.4 \%)$. However, $58(11.6 \%)$ of the surveyed firms indicated they do not have an Internet-based e-business and 74 (14.8\%) do.

\subsection{Demographics of the survey group}

The analysis of the responding firms with Internet-based electronic business revealed that $60 \%$ of the respondents were manufacturing and $40 \%$ service. 
The significant majority of the manufacturing companies (92\%) and service firms $(89 \%)$ were privately owned. More manufacturing companies $(77 \%)$ than service organizations (52\%) conduct business both nationally and internationally; $77 \%$ of manufacturing and $52 \%$ of service corporations buy and sell globally. All manufacturing and $69 \%$ of service companies use the B2B model. The B2C model is used by 97 and $43 \%$ of service and manufacturing firms, respectively. The majority of service firms $(85 \%)$ and manufacturing companies $(60 \%)$ had their latest e-business implementation in the last 5 years.

\section{Development and implementation of e-business}

Three questions in the study solicited data with regard to the development and implementation, maintenance, and technical support for e-business models in use. Table 1 shows that the majority of the respondents developed their ebusiness models and most of these systems are maintained and supported by in-house technical staff.

Study participants were asked if the implementation of e-business was based on an e-business strategy. More manufacturing organizations (67\%) than service firms (53\%) had developed an e-business strategy before implementing e-business. Full integration of e-business into business processes was reported by $72 \%$ of manufacturing and $83 \%$ of service companies. Another question in the survey dealt with online purchasing and procurement. Almost the same percentages were reported for online procurement by manufacturing firms (70\%) and service organizations (69\%). It appears that Swedish SMEs are taking advantage of this aspect of electronic business.

\section{Cost reduction and increase in sales}

The majority of the firms in the study group, $87 \%$ of manufacturing and $76 \%$ of service organizations reported that the use of electronic business has resulted in reducing the costs of doing business. Table 2 presents the percentage of cost reduction for the participants.

Table 1 E-business development and support

\begin{tabular}{|c|c|c|c|c|}
\hline \multirow[t]{2}{*}{ E-business } & \multicolumn{2}{|c|}{ Manufacturing } & \multicolumn{2}{|l|}{ Service } \\
\hline & $\begin{array}{l}\text { In-house } \\
(\%)\end{array}$ & $\begin{array}{l}\text { Outsourced } \\
(\%)\end{array}$ & $\begin{array}{l}\text { In-house } \\
(\%)\end{array}$ & $\begin{array}{l}\text { Outsourced } \\
(\%)\end{array}$ \\
\hline Development and implementation & 59 & 41 & 57 & 43 \\
\hline Managed and maintained & 95 & 05 & 87 & 13 \\
\hline Technical support & 74 & 26 & 69 & 31 \\
\hline
\end{tabular}


Table 2 Cost reduction due to e-business use

\begin{tabular}{lll}
\hline Cost (\%) & Manufacturing (\%) & Service (\%) \\
\hline$<10$ & 77 & 06 \\
$10-20$ & 23 & 41 \\
$20-30$ & - & 53 \\
\hline
\end{tabular}

Although both groups have experienced savings in their business from the implementation of e-business, a higher percentage of service organizations (94\%) than manufacturing $(23 \%)$ have saved $10 \%$ or more. Considering that various technologies have been used by manufacturing firms over the last few decades to streamline their processes and to reduce the cost of production, it is not surprising to see that cost savings is less for this group.

One of the advantages of conducting business online is that it is convenient for the customer to order and in return, this feature of business could increase sales volume. More service (46\%) than manufacturing (42\%) firms reported an increase in their sales volume because of e-business implementation.

\section{E-business champion}

The survey respondents identified the most influential person or department in their move toward e-business implementation. Table 3 depicts the results. A comparison of the two groups shows that in service firms the CEO/owner championed the e-business implementation followed by marketing and sales. However, in manufacturing firms the marketing and sales department was instrumental in persuading the organization to implement e-business.

\section{Length of implementation}

One of the areas of consideration in the implementation of any new technology is the time that it takes to acquire the hardware and software needed for the project as well as integration and user training. The questionnaire sought information about the time that it took to implement an e-business system. The majority of the respondents (46\% of manufacturing and $52 \%$ of

Table 3 The most influential in e-business implementation

\begin{tabular}{lll}
\hline Most influential & $\begin{array}{l}\text { Manufacturing } \\
(\%)\end{array}$ & $\begin{array}{l}\text { Service } \\
(\%)\end{array}$ \\
\hline CEO/owner & 10 & 37 \\
Production/manufacturing & 03 & - \\
Information technology department & 13 & 22 \\
Marketing and sales & 59 & 26 \\
Purchasing/procurement & 10 & 11 \\
Finance/accounting & 02 & - \\
Employees & 03 & 04 \\
\hline
\end{tabular}


service firms) reported that it took them between 6 and 12 months to have the e-business system ready for use.

More manufacturing than service firms experienced implementation time of over 18 months as shown in Table 4. The data seem to provide evidence that most SMEs can implement an e-business system within a year. This information is useful to those SMEs that are planning to integrate electronic business in their organizations.

\section{E-business security and privacy}

When conducting business electronically and over the Internet, the security of data transmission of buyers, business partners, and suppliers is a critical issue for businesses. The integrity and the privacy of information exchanged among customers and sellers must be protected at all times. To gain customers' trust and assure them that their site is safe, many organizations display security seals on their website ( $\mathrm{Hu}$ et al. 2003). Privacy and security issues should be addressed in the e-business strategy and a policy statement should be developed governing privacy and security matters (Patton and Josang 2004; Thuraisingham 2005; Shih and Wen 2005).

Small and medium enterprises may be more at risk since they might not have the expertise and financial means to guard against unauthorized access to the confidential information by employees and from outsiders and hackers. Business owners and managers must take steps to assure the business partners and the customers of the security of their network when business transactions are performed online. In the December 2004 issue of Risk Management Magazine, it was reported that e-business was the most hit area of the computer technology attacks. The survey participants were asked if their computer network security has been breached over the last 2 years. The majority of service $(87 \%)$ and manufacturing $(89 \%)$ had no security problems with their system either internally or externally. However, those manufacturing $(11 \%)$ and the service (13\%) firms who had experienced unauthorized access to their system reported one incident (33\% manufacturing and $20 \%$ service) and two occurrences by $67 \%$ of manufacturing firms and $80 \%$ of service organizations. No company had experienced more than two incidents.

Table 4 Time to implement e-business

\begin{tabular}{lll}
\hline Months & Manufacturing (\%) & Service (\%) \\
\hline $1-6$ & 28 & 37 \\
$7-12$ & 46 & 52 \\
$13-18$ & 14 & 07 \\
Over 18 & 12 & 04 \\
\hline
\end{tabular}




\section{Completion time and budget}

Information technology projects such as the implementation of electronic business and web technologies are both time and cost sensitive. An important step toward a successful e-business implementation is the selection of a project manager who has a good understanding of the business and the technologies involved in the project. Project management tools such as a Gantt chart, critical path method (CPM), program evaluation review technique (PERT), or Microsoft Project are useful to estimate project completion time and budget, evaluate progress, and signal delays.

Managers/business owners of SMEs should consider e-business acquisition and implementation as a capital investment decision and allocate adequate resources to the project. In order to ensure satisfactory implementation, top management must be involved in the development of an implementation plan, be the driving force behind every phase of the implementation, and resolve any problems encountered to secure the desired outcome.

A budget to cover the costs of implementation and a detailed schedule of activities associated with e-business functions from the start of implementation to the end should be developed. Table 5 provides the data for e-business completion time and budget. It is worth noting that, on the one hand, the majority of the manufacturing firms (72\%) and service companies $(67 \%)$ who reported satisfactory implementation of e-business models finished the project either ahead of schedule or on time and within budget (63\% of manufacturing and $61 \%$ of service firms). On the other hand, the majority of dissatisfied manufacturing $(86 \%)$ and service $(68 \%)$ organizations were behind schedule on e-business implementation and experienced cost overruns. When developing an e-business strategy, provisions for delay of completion time and extra project costs due to unforeseeable events should be made.

\section{Online business}

By integrating e-business activities with the corporate website, companies can sell products online, have online billing and payments, provide customer service, and inform the customer about new sales and promotions among

Table 5 E-business completion

\begin{tabular}{llllll}
\hline \multirow{2}{*}{ Time and budget } & \multicolumn{2}{l}{ Satisfactory } & & \multicolumn{2}{l}{ Unsatisfactory } \\
\cline { 2 - 3 } & Manufacturing (\%) & Service (\%) & & Manufacturing (\%) & Service (\%) \\
\hline Ahead of schedule & 16 & 0 & 0 & 0 \\
On-time & 56 & 67 & & 14 & 32 \\
Behind schedule & 28 & 33 & & 06 & 0 \\
Under budget & 6 & 0 & & 0 & 37 \\
Within budget & 63 & 61 & & 23 & 63 \\
Over budget & 31 & 39 & 77 & \\
\hline
\end{tabular}


others. The survey results showed that more service companies $(70 \%)$ than manufacturing firms $(56 \%)$ sell products online. Customer support is provided online by $45 \%$ of manufacturing and $63 \%$ of service organizations. More manufacturing participants $(60 \%)$ engaged in online billing and payments than service $(52 \%)$. Online product customizations were allowed by $18 \%$ of manufacturing and $7 \%$ of service firms. The majority of services $(64 \%)$ indicated they send e-mail to customers for new sales and promotions as opposed to $43 \%$ of manufacturing.

When designing a website, the designers must incorporate key words for search queries to get the customer to the site. Companies can pay an Internet placement firm to ensure a top spot for the company's website on the search engine. The majority of respondents (79\% of manufacturing and $85 \%$ of service firms) did not invest in an Internet placement service. However, the majority of those who did (67\% of manufacturing and 59\% of service companies) expressed that the investment generated positive results.

\section{Barriers to entry}

Before venturing into e-business, many factors such as cost, change of corporate culture, security, availability of resources, resistance to change by employees, and integration of e-business into business activities should be considered by managers. It has been argued that these factors collectively and independently could inhibit SMEs from implementing e-business (Kosan 2001; Fillis et al. 2004; Taylor and Murphy 2004; Mendo and Fitzgerald 2005). The survey respondents rated the degree of importance given to barriers to e-business entry before implementation on a scale ranging from 1 (no importance) to 5 (maximum importance). The results are given in Table 6. As expected, the cost of having and maintaining an e-business system in both sectors were the highest pre-implementation concern to SME managers with a score of 4.12 and 3.86 for manufacturing and service, respectively, out of a maximum of five.

The second highest scores in both sectors were given to shortage of resources. The results show clearly that the lack of adequate financial and personnel resources could be major impediments to SMEs in implementing

Table 6 Barriers to ebusiness investment: average rating (1-5)

\begin{tabular}{lll}
\hline Barrier & $\begin{array}{l}\text { Manufacturing } \\
\text { (mean) }\end{array}$ & $\begin{array}{l}\text { Service } \\
\text { (mean) }\end{array}$ \\
\hline Security concerns & 3.46 & 3.36 \\
Shortage of resources & 3.94 & 3.72 \\
Corporate culture & 2.35 & 2.21 \\
Resistance to change by employees & 1.96 & 1.98 \\
Integration disruption & 3.59 & 3.53 \\
Cost of e-business implementation & 4.12 & 3.86 \\
$\quad$ and maintenance & & \\
\hline
\end{tabular}


e-business. Resistance to change by employees received the lowest rating by both manufacturing and service firms. This is not unexpected since preparing employees for change is easier in SMEs than large corporations because the communications channels between management and employees are less bureaucratic and formal in SMEs.

\section{The impact of e-business implementation}

Integration of e-business technology into business processes can reduce unit cost of goods and services provided by lowering personnel requirements and reducing both transactions and agency costs of the business. E-business is a way for companies to become more efficient and to promote operational flexibility. Responsiveness to consumer needs and supplier relations can be improved. In addition, these companies are able to collect data about their customers to improve marketing strategies, sales, and customer service.

The survey also asked respondents to score the degree of improvement they experienced after e-business implementation with regard to several key performance areas. The results are shown in Table 7. Scores ranged from 1 (no improvement) to 5 (most improvement). Improvement in the area of customer service scored the highest degree (3.84 in manufacturing and 3.91 in service) of all the performance areas in both sectors. The data indicate that e-business can be used by SMEs to improve communications between the customer and the organization which in turn can translate into customer satisfaction and retention. The scores for customer service and retention are similar for the two sectors.

The service organizations have benefited more in the areas of product promotion, advertising, and marketing than manufacturing firms. The costs of product handling and distribution of goods to wholesalers, retailers, and customers are generally higher in manufacturing than service firms. The data show that manufacturing firms (3.32) using e-business benefited more in these areas than service corporations (2.74).

In order for organizations to realize the maximum benefits of the e-business technology, managers must create a compatible organizational structure with e-business applications. Matching employees' activities with e-business

Table 7 Areas improved by e-business implementation: average rating (1-5)

\begin{tabular}{lll}
\hline Performance & $\begin{array}{l}\text { Manufacturing } \\
\text { (mean) }\end{array}$ & $\begin{array}{l}\text { Service } \\
\text { (mean) }\end{array}$ \\
\hline Product promotion & 3.10 & 3.60 \\
Distribution costs & 3.32 & 2.74 \\
Customer service & 3.84 & 3.91 \\
Customer retention & 3.62 & 3.69 \\
Acquisition of new customers & 3.19 & 3.24 \\
Advertising & 2.75 & 3.24 \\
Marketing & 3.01 & 3.80 \\
\hline
\end{tabular}


applications requires change in the corporate culture which is the softer side of the corporate structure and is the set of values that employees share in the enterprise. Proper management of cultural change can be a critical factor in the successful implementation and the use of e-business technology. E-business technology affords the company to move from a traditional business model to a model that promotes shared activities, decision making, and problem solving as well as strengthening the management of inter- and intraorganizational processes. Change of organizational structure and the business model allow the firm to be flexible and to improve internal and external information flow, reduce inventory costs, and to better manage its supply chains and customer relationships.

The survey respondents identified the extent of the impact of e-business on their organizations in ten different areas on a scale ranging from 1 (no impact) to 5 (highest impact). Table 8 depicts the results. The highest impact in the manufacturing group was given to inventory management (4.02) and in the service to customer relationship management (3.88). Given that the manufacturing firm's responsiveness to customer demands depend on an effective management of inventory and the efficiency of the supply chain performance, it is not surprising to see that the manufacturing sector gave the highest rating to inventory management. Both groups rated the improvement in their supply chains as the second highest.

As mentioned earlier, e-business integration requires that organizations change their business model as well as the corporate culture. Both sectors reported that e-business implementation changed their business model (3.37 rating by manufacturing and 3.28 by service) and corporate culture with ratings of 3.86 and 3.64 for manufacturing and service, respectively.

E-business can provide organizations with the ability to increase sales and profitability by using electronic networks to reach customers without regard to their geographic locations and be more flexible in the production and delivery of goods and services to the marketplace. The scores for improved profitability ranked the fifth highest and are very similar between the manufacturing and service firms. Both groups improved corporate agility by implementing e-business technology (3.64 reported by service and 3.59 by manufacturing).

Table 8 The overall impact of e-business on the organization: average rating (1-5)

\begin{tabular}{lll}
\hline Area & $\begin{array}{l}\text { Manufacturing } \\
\text { (mean) }\end{array}$ & $\begin{array}{l}\text { Service } \\
\text { (mean) }\end{array}$ \\
\hline Changed corporate culture & 3.86 & 3.64 \\
Changed our business model & 3.37 & 3.28 \\
Improved supply chain & 3.92 & 3.81 \\
Accounting and finance & 3.07 & 3.12 \\
Organizational communications & 3.23 & 3.48 \\
Inventory management & 4.02 & 2.85 \\
Increased market share & 2.81 & 3.14 \\
Improved corporate agility & 3.59 & 3.64 \\
Customer relationship management & 3.79 & 3.88 \\
Improved business profitability & 3.60 & 3.56 \\
Composite index & 3.53 & 3.44 \\
\hline
\end{tabular}


The least amount of impact was felt by manufacturing (2.81) in gaining market share and by service (2.85) in the area of inventory management. While inventory management is an important factor in manufacturing and retailing companies, it is not a major issue for most service businesses.

Finally, the composite score for SMEs, a simple average of the ten areas, showed a slightly higher score for the manufacturing than service sector. Clearly, the results demonstrate that the overall impact of the e-business on these companies has been positive and both manufacturing and service firms benefited from investing in e-business technology.

\section{Conclusions}

Information and communications technologies have become part of the daily activities of consumers and businesses alike. Small and medium-size enterprises as a whole are a major contributor to the national wealth of modern economies. More than $99 \%$ of businesses in the member states of the European Union are SMEs. These enterprises are using information and communications technologies more than ever before to improve their business processes and to link with customers and business partners. In Sweden, 96\% of SMEs employ these technologies for administrative, business communications, and operational activities (Taylor and Murphy 2004).

The main objective of this research was to examine the impact of electronic business on both manufacturing and service SMEs in Sweden. The study focused on the data collected from SMEs that use e-business in their day-to-day business activities. The findings provide valuable information to the SME owner/manager who is interested in implementing e-business.

The best approach to implement a successful e-business is the development of an e-business strategy. This method provides an opportunity for the owner/ manager of an SME to focus on the changes that adoption of e-business will require on the business model and processes for the long-term success of the enterprise. The majority of the service and manufacturing firms in the study had developed an e-strategy for e-business integration and were able to complete the project within a year and within budget.

Marketing and sales were the most influential in the adoption of e-business in the manufacturing group whereas in the service group the CEO/owner was most influential followed by marketing and sales. Clearly, the marketing and sales functional area plays an important role in e-business adoption in both sectors. The cost of e-business implementation was considered to be a major barrier for adoption followed by shortage of resources, integration disruption, and security concerns by both groups.

The findings of this research suggest that although e-business implementation may be considered an expensive and disruptive technology by managers of SMEs, in the long run the benefits derived from the diffusion of e-business will outweigh the costs. Future studies can focus on industry type and the competitive nature of SMEs that use e-business and those that do not. 


\section{References}

Barau A, Konana P, Whinston A, Yin F (2001) Driving e-business excellence. MIT Sloan Manage Rev 43(1):36-44

Cote L, Vezina M, Sabourin V (2005) The strategic management process in business. Ivey Bus J 17

Evans N (1999). Flexibility, adaptability are key to e-business. InternetWeek, 16

Fillis I, Johannson U, Wagner B (2004) Factors impacting on e-business adoption and development in the smaller firm. Int J Entrep Behav Res 10(3):178-191

Grandon E, Pearson JM (2004) Electronic commerce adoption: an empirical study of small and medium US businesses. Inf Manage 42:197-216

Hu X, Lin Z, Zhang H (2003) Trust promoting seals in electronic markets: an exploratory study of their effectiveness for online sales promotion. J Promot Manage 9(1/2):163-180

Internet Usage in Europe (2006) Available at http://www.internetworldstats.com/stats4.htm

Kosan L (2001) E-business eats up culture-firm's soft skills predict. eWeek, p. 58

Lefebvre LA, Lefebvre E, Elia E, Boeck H (2005) Exploring B-to-B e-commerce trajectories in manufacturing SMEs. Technovation 25:1443-1456

Mendo FA, Fitzgerald G (2005) A multidimensional framework for SME e-business progression. J Enterp Inf Manage 18(6):678-696

Patton MA, Josang A (2004) Technologies for trust in electronic commerce. Electron Commer Res 4:9-21

Peet S, Brindley C, Ritchie B (2002) The European Commission and SME support mechanisims for e-business. Eur Bus Rev 14(5):335-341

Quayle M (2002) E:business: the challenge for UK SMEs in the twenty-first century. J Oper Prod Manage 22(10):1148-1161

Risk Management Magazine (2004) December, p. 9

Sanderson J (2004) Opportunity and constraint in business-to-business relationships: insights from strategic choice and zones of manoeuvre. Supply Chain Manage Int J 9(5):392-401

Shih SC, Wen HJ (2005) Integrated e-enterprise security design and implementation: a case study of e-service in supply chain management. Int J Electron Bus 3(2):154-173

Straub D, Klein R (2001) E-competitive transformations. Bus Horiz 44(3):3-12

Taylor M, Murphy A (2004) SMEs and e-business. J Small Bus Enterp Dev 11(3):280-289

Thuraisingham B (2005) Directions for security and privacy for semantic e-business applications. Commun ACM 48(12):71-73

Wright B (2000) E-Business: the great IT catalyst. Manufacturing computer solutions: IT strategy issue 19-20 